\title{
Advertising Social Semiotic Representation: A Critical Approach
}

\author{
Maryam Najafian (Corresponding author) \\ Department of English Language and Literature, Faculty of Foreign Language \\ Hezarjarib Street, University of Isfahan, Isfahan, Iran \\ Email:m.najafian56@yahoo.com \\ Saeed Ketabi \\ Assistant professor of Applied Linguistics \\ Department of English Language and Literature, Faculty of Foreign Language \\ Hezarjarib Street, University of Isfahan, Isfahan, Iran \\ Email: ketabi@fgn.ui.ac.ir
}

Received: July 05, 2011 Accepted: July 14, 2011 DOI: 10.5296/ijim.v1i1.775

\begin{abstract}
The aim of this article was to show the usefulness of a Social Semiotics approach proposed by Kress and van Leeuwen (2006) in analyzing advertising discourse to achieve the aim of uncovering the ideology behind choosing different resources (verbal and non verbal). Two examples selected from 'Time' magazine showed that both textual and visual signs are among social semiotic resources which could help advertisers to convey persuasive messages under ideological assumptions. The result of this study revealed that social semiotic reference occupies a pivotal point in the relationship between advertising discourse and ideology. The image, word and color, seen in this way as the product of social practices, are just three of the many semiotic modes through which social meanings of advertisements are coded.
\end{abstract}

Keywords: Print advertising, Social Semiotic Analysis, Ideology, Critical Approach 


\section{Introduction}

Williamson (1978: 19) believes that an advertisement does not create meaning at the first time but invites us to make a transaction where it is passed from one thing to another. This claim is supported by Saren et al. (2007: 128), "advertisements utilize a pre-existing referent system of meaning, because the product, prior to signification in the advert, has no meaning". Cook (1992: 5) states that "advertising is a prominent discourse type in virtually all contemporary societies, and we live in a society where it is already well established_or rapidly gaining ground. The important distinguishing feature of ad discourse is its function; because this is always to persuade people to buy a particular product". But, this is not the only function. According to Durant and Lambrou (2009: 93), at the same time, "advertising conveys information, so that consumers know what is available, who makes it, and where and how they can get it".

Goldman (1992: 2) reads ads socially by identifying advertising as a key institution in "producing and reproducing the material and ideological supremacy of commodity relations". He calls this system' commodity hegemony'; because, "they reproduce a sense of commodity relations as a natural and inevitable part of the lives of different individuals" (Saren et al., 2007: 129). As Williamson (1978) points out, "ads ask us to participate in ideological ways of seeing ourselves and the world". Eagleton (1991: 9) define ideology as a matter of 'discourse' rather than 'language'. "It concerns the actual uses of language between particular human subjects for the production of specific effects. He believes that you cannot decide whether a statement is ideological or not by inspecting it in isolation from its discursive context"(ibid.). According to him the term 'ideology' is just a convenient way of categorizing under a single heading a whole lot of different things we do with signs. According to Hodge and Kress (1993: 212) "ideological forms are structures of meaning (versions of social relationships) that are inseparable from a set of practices that are themselves kinds of meaning". Ideological analysis of discourse must take full account of the ideologies inscribed in discursive practice. Hence, in order to gain a deep insight of the role that advertising plays in our society, it seems to be necessary to ask how advertising makes reality, how ideology and meanings are produced within the ad discourse, and why images and signs are the way they are.

Dyer (1986: 129) holds that "ads as a means of representation and meaning construct ideology within them through the intervention of external codes which are located in society". He believes that the ideology of advertisements is so powerful; it is naturalized by the image, the neutral realm of signifier (ibid.). Ideological powers, as Eagleton (1991: 195) puts it, are not just "a matter of meaning", but of "making a meaning stick". Saren et al. (2007: 31) argue that:

"The semiotic analysis of ads assumes that the meanings of ads are designed to move out from the page or screen on which they are carried, to shape and lend significance to our experience of reality. We are encouraged to see ourselves, the products or services which are advertised, and aspects of our social worlds, in terms of the mythic meanings which ads draw on and help to promote". 
Van Dijk (1995: 17) states that, "ideologies are typically, though not exclusively, expressed and reproduced in discourse and communication, including non-verbal semiotic messages, such as picture, photographs and movies". Advertising has a specific contribution to the construction of a global village, the partial understanding of the external worlds. The textual analysis proposed by Fairclough (2003) addresses a diverse range of features of texts such as direct address to audiences, modality, nominalization, passive voice, vocabulary and rhetorical and persuasive features of texts. Goatley (2000) investigated the obvious and less obvious ideological strategies in and behind advertisements and gives some important aspects of consumerist ideology used by copywriters. Bloor and Bloor's (2007) 'The Practice of Critical Discourse Analysis' seeks to develop readers' awareness of language and ideology and provides practice in analytic skills applied to various type of discourse such as advertising.

Kress and van Leeuwen (2006) introduce the existence of "a visual code" or "grammar of visual design". They believe that both visual structures and verbal structures can be used to express meanings drawn from common cultural sources. They state that, "Like linguistic structures, visual structures point to particular interpretations of experience and forms of social interactions" (Kress and Van Leeuwen, 1996: 2). Hence, Barthes' paradox is solved through considering the codes embedded in all forms of visual communication which are the forms by Kress and Leeuwen definitions and are, or should be an important part of the critical disciplines. An advertisement, like any semiotic entity such as a book and child's drawing is the result of design. According to Kress (2010: 43) "design is shaped by the prior analysis provided by the rhetor through questions such as:' What is the environment of communication?', ' What relations of power are at issue?', and ' What resources are available to make the message?', ' What is the phenomenon to be communicated?', and ' What resources are available to make the message?"' In the case of advertising, the rhetor is an advertiser who in the persuasive environment with resorting to all kinds of resources makes an attempt to get the likely responses of an imagined audience in different ways, with different conceptions of purpose, power and affect.

Simpson and Mayr (2010) in a recent book entitled Language and Power outline key theoretical and methodological principles of CDA proposed by Fairclough and Wodak (1997) and their implications for analyzing ads. Simpson and Mayr (2010: 87) state that; some questions might inform a Critical Linguistic Analysis of advertising discourse such as:

i) What ideological assumptions are encoded in the advertisement?

ii) Is there any ideological significance about the manner by which the commodity is marked?

The main aim of this article is to apply the Social Semiotics model proposed by Kress and van Leeuwen (2006) to identify an ideology in two sample ads. The sample is located within October editions of the popular magazine, namely 'Time'. Thus this essay will individually analyze these advertisements in terms of their status as signs, whose associative meanings not only give a favorable impression of the product, but are also compatible with, and 
complementary to, the cultural context in which they are situated; thus illustrating the claim that the medium and message may be charged with cultural signification. The present study will address the following research questions:

i) What linguistic and social semiotic resources are used by ads producers in advertising discourse?

ii) Is there any ideological significance in using linguistic and semiotic resources?

\section{Print Advertising}

Print advertising creates a medium for understanding how advertisers attempt to persuade potential readers. Bignell (2002) states that, "photographs used in print advertisements work as a system of signs that gives form and meaning to consciousness and reality". Kress (2010: 62) believes that:

"The sign is the central concepts of semiotics. In the sign, meaning and form are fused into one entity. In a Social Semiotic theory, signs are made_ not used_ by assign- maker who brings meaning into an apt conjunction with a form, a selection/choice shaped by the sign-maker's interest".

According to van Leeuwen (2005: 8), "a good starting point for studying aspects of visual communication is to consider that there are two verbal and visual modes of communication in print advertising with complex interaction between them". It can be conceived that the linguistic as well as visual choices made by ad producers are not accidental at all. It is believed that Critical discourse analysis (CDA) can uncover the ideologically-laden choices in this particular discourse.

In this way, the present study adopts the semiotic approach of Michael Halliday (1994), namely that a full theory of communication will need to represent meanings about actions, states, events in the world, the ideational function; to represent meanings social relations of those engaged in communication, the interpersonal function; and have the capacity to form texts with all semiotic entities which have internal and external coherence, the textual function. Kress and van Leeuwen (2006: 32) propose that "visual communication is always coded. Societies tend to develop ways for talking about codes only with respect to codes that are highly valued. These codes play a significant role in controlling the common understandings of any societies and are the essential needs they require to function".

Bignell (1997: 78) believes that "when scanning the print ads, the qualities that bring it together and set it apart from other media are ones that could be labeled, 'artistic'; the range of color, the sense of sign, intertextuality and the 'beauty' of the forms". He states that the magazine is "just a collection of signs. These signs may include paradigmatic and syntagmatic elements such as the title of the magazine, the fonts used, the layout, the colors, the texture of the paper, the language adopted, the content of the articles and so on, and each of these signs have been chosen to generate a meaning"(ibid.). 


\section{A Social Semiotic Approach and Ideology}

According to Bignell (2002: 32), "the first step in analyzing an advertisement is to note the various signs in the advertisement itself". It could be assumed that anything which seems to carry a meaning for us in the ad is a sign. Then, linguistic signs (words) and iconic signs (visual representations) are likely to be found in ads, as well as some other non-representational signs like graphics.

The sample used in the detailed critical discourse analysis consists of two ads extracted from 'Time' magazine issued 2002. The rational for choosing 'Time' magazine is that; it is popular mainstream magazine that which is being published for more than 80 years and still is available in most newsagents; and can be seen as part of the global media. In this study, both verbal and non verbal signs have been analyzed critically from 'semiotic landscape' to find their interdiscursal features according to what proposed by Kress and van Leeuwen (2006). They state that "in order to function as a full system of communication, the visual, like all semiotic modes, has to serve several representational and communicational requirements" (Kress and van Leeuwen 2006: 41). Hence, "social semiotics is concerned with the social meanings constructed through the full range of semiotic forms, through semiotic texts and semiotic practices" (Hodge and Kress 1988: 261). In social semiotic, the smallest semiotic form that has concrete existence is the 'message'. Hodge and Kress (1988: 5) argue that the message has "directionality_it has a source and a goal, a social context and purpose".

According to Dyer (1986: 130), since "denotation is not neutral or untouched by ideology, whatever image is being used some sort of meaning is attached that goes beyond the literal meaning". On the connoted level because it is not neutral it is set within society - the ad cannot simply "reflect ideology, it reworks it, thus producing new meanings" and "this connotation process depends on our knowledge of the forms of ideology that advertisements employ" (Dyer, 1986: 129-130). These meanings are socially made, socially agreed and consequently socially and culturally specific.

\subsection{Textual Analysis}

Appendix 1 shows 'OMEGA' watches ad issued in 2002. In this advertisement, the advertiser has used larger, capital and bold letters in the headline in order to perhaps draw receiver's attention and make them curious about what this advertisement is mainly about. This may lead the readers to go on reading and arouse their curiosity and desire to know more about the product and finally may reach its goal to persuade the readers to buy it. In the first ad (See appendix1), there is a headline, which interacts with the image (Michael Schumacher's Choice), the body copy, which takes up the bottom part of the ad with the product itself (World champion Michael Schumacher chooses the speed master racing). A closer look at the ad shows, that it employs some widely used linguistic features in advertising, namely disjunctive syntax, indirect address and conjunctive adjuncts. According to Bernstein (1974) reason ads can be characterized by i) conspicuous product placement along with brand name and (if available) company logo visually prominent and ii) a clear and unambiguous slogan giving the principle reason to buy the product (Cited in Simpson \& Mayr 2010: 93). Halliday (1994: 36) states that "what seems to mark reason ads out more than any other characteristic, 
however, is their particular use of a set of text- building devices known as conjunctive adjuncts". One type of conjunctive adjunct used in this ad is 'causal', which is hidden in the body copy. It appears if we add the causal, because, in the beginning of that sentence.

(Because, World champion Michael Schumacher chooses the speed master racing).

"Yet another strategy to mimic a conversational style in ads is the use of disjunctive syntax" (Delin 2000: 129); that is the use of sentences without verbs or subjects, or sentences consisting of one or two grammatical elements only. Here the headline (Michael Schumacher's Choice) falls into this category.

Let us now consider the linguistic features of the second advertisement. The top part of this ad consists of the headline, 'Cindy Crawford's Choice', which interacts with the photographed female. Here we can see that it employs one widely used linguistic feature in advertising, namely disjunctive syntax. Advertising makes use of this feature for both ideological and practical reasons. Ideologically, it may use no active or passive verbs in order to put it on the viewer to judge about the actor in the advertisement. Practically, the main aim of ads is to persuade readers to buy or do certain things and therefore they often contain celebrities' names and pictures.

According to Morris and Hirst (1991), lexical chains are sequences of related words in text. The most direct and obvious form of lexical cohesion is the repetition of positive adjectives, such as successful or of (the highest) quality, which explicitly evaluates the subject discussed. Table 1 shows the various positive adjective used in the body copy of this ad in order to make lexical cohesion.

Table 1. Lexical Cohesion. References to the success of an organization, its products or

Services

\begin{tabular}{|l|l|}
\hline Source & \multicolumn{1}{c|}{ References to success } \\
\hline Ad 2 & $\begin{array}{l}\text { The Omega Constellation is a rare blend of style and elegance. A superb } \\
\text { example of the watchmaker's art. This is no wonder, since Cindy Crawford } \\
\text { assisted Omega in its design. Creating the only watch she is proud to wear. }\end{array}$ \\
\hline
\end{tabular}

According to table1, the body copy, in the bottom part of this ad with the product and the photographed female make a coherent chain. The body copy consists of linguistic features such as; adjectives. The ad analyzed uses vocabulary which has to do with promotion. According to Cook (1992) and Jefkins (1994), headline key characteristic is the use of positive words. As Fowler (1985: 65) argues vocabulary might be seen as a map "of the preoccupations of a culture [...]. Detailed systems of terms develop for the areas of expertise, the features of habitat, the institutions and relationship, and the beliefs and values of a community". Use of positive words such as, rare, style, elegance, totally, superb, the only and proud in ad2 contributes to the co-referentiality of the success of the company, its products or 
services.

Delin (2000: 133) believes that adjectives play a key role in advertising because they often convey "positive or negative affective meaning". Affective meaning displays the speaker's or writer's positive or negative evaluation of the item referred to.

Also, in this ad there is a syntagm of linguistic signs, 'Cindy Crawford's Choice'. To read this ad, we could identify the connotations of the signs present in it. Seeing how the anchorage between the picture and the text directs us towards the 'correct' reading of the advertisement. The relay between the watch denoted iconically in the ad and the linguistic sign 'Cindy Crawford Choice' makes it easy to see that this is a special watch product for women. According to Beasley and Danesi (2002: 17), "the ultimate goal of creating an appropriate image for a product is to embed it into social consciousness". The mythic meanings of the ad as a whole seem to be that the woman, the watch, and the reader, can mean several things at once. The woman, the watch and the reader are not single and fixed identities, but sites where several different coded social meanings in this ad oscillate back and forth. We do not need to decide on a single social meaning for the watch, the woman who wears it in the picture, or for ourselves as readers of the ad or buyer of the watch. The ad invites us to enjoy the unanchoredness of its signs, and the multiplicity of the watch social meanings. This ad addresses women, presenting them with a sign connotating sexual attractiveness and power (the woman wearing the watch).

These social meanings, according to the ad can be attained by women if they buy the watch. According to the notions proposed by Kress and van Leeuwen (2006), "there are a number of coherent alternative ways of reading the ad, and a number of possible subject-positions from which to understand it".

\subsection{Social Semiotic Analysis}

Kress and van Leeuwen (2001) state that, "at the level of the social organization of semiotic production different configuration of discourse, design, production and distribution may occur". They see multimodal texts as making meaning in multiple articulations.

\subsubsection{Placement of signs}

The placement of the image is very important. In both ads, the advertiser has made an attempt to attract their readers' attention by placing one image of watch in the centre of these advertisements and above that endorsing one human image. It is a large colored image which occupies three- quarters of the ad; a relatively small section is devoted to verbal signs. This implies that this human image is the central means of conveying meaning. In addition, based on what stated by Kress (2010), it is functionally dominant in carrying major 'informational load' of the image. The text is functionally subordinate. The body copy reinforces this idea as it is placed directly underneath the image in a contrasting black font. At the same time, the advertisement uses smaller-than-headline letters for the body copy perhaps to make it attractive, eye catching and clear for the readers. These watch ads invite us to recognize the connotations of the signs, and to transfer these connotations to the product being advertised. The design of the first ad watch device (see appendix1) could emphasize their 'sporty' 
characteristics. The body copy reinforces this claim. This could lead the audience to the functionality of this watch as highly usable for sports men. However, where speed and time are predetermined, in one social context, it is inevitable that different kinds of human social dispositions and, identities will come to evolve with the use of this product.

The first watch ad, by placing the photographed famous driver man 'Michael Schumacher' above the product actively constructs a relationship between the man and the product. Schumacher was noted throughout his career for his ability to produce fast laps at crucial moments in a race, to push his car to the very limit for sustained periods. Beasley and Danesi (2002) believe that ads endorsed by celebrities to make a product appear reliable. They do this by placing an iconic sign (the photographed man) and a linguistic sign next to each other. Since the relationship involves the sharing of the mythic meanings 'accuracy', 'speed' and 'time' by both the photographed man and the product, "it is this relationship between one sign and another which is important for the meaning of the ad" (Bignell 2002: 34).

Appendix 2 shows another 'OMEGA' watches ad issued in 2002. A picture of a beautiful female supermodel 'Cindy Crawford' in this ad is not simply a sign denoting a particular person who has been photographed. The picture of the supermodel is also a sign which has connotations like youth, slimness etc. According to Bignell (2002) because a "sign has these positive connotations; it can work as the signifier for the mythic signified 'feminine beauty'. This concept belongs to our society's stock of positive myths concerning the attributes of sexually desirable woman". The ad has presented us with a sign (the photographed model) which itself signifies a concept 'feminine beauty'. This concept of feminine beauty is what Barthes (1964) would describe as a mythic meaning. The mythic meaning of the ad connected the watch, feminine beauty, and exotic sexual pleasure. As in the case of Barthes' black soldier saluting the flag, it does not matter who the model is, who the photographer was, where the picture was taken, etc. The only significant attribute of the photographed model is that she exhibits the physical qualities which enable her to function as a signifier for the mythic meaning 'feminine beauty'. Bignell (2002: 33) believes that, "photographic sign has been emptied of its meaning except in as much as it leads the reader of the ad towards comprehending the myth". The connotative meanings are the ingredients of myth, the overall message about the meaning of the product which the ad is constructing by its use of the photographed model.

Watch ads do not literally announce that a watch will make you seem beautiful (this claim would be illegal in many societies anyway). Instead this message is communicated by the structure of signs in the ad, by the way that we are asked to decode the ad's mythic meanings. The positive connotations of women used as signs derive from the positive connotative in western culture. Bignell (2002: 34) states that, "ads call on systems of differences which already exist in our culture, and which encode social values". It is easy to see that the ideological view of feminine beauty in ad2 is not 'natural' but cultural if we compare the representations of women in western cultures with eastern cultures. In some parts of the world like Muslim countries, the ideological myth of feminine beauty is not always could be different. 


\subsection{3 'Given' and 'New' in Advertising}

According to Kress and van Leeuwen (2006: 211) in any sequential structure, "that which is about to be said or shown is by definition always 'New', not yet known. By contrast, what has (just) been seen, heard, discovered is, by comparison, now known, 'Given'". In these two ads both images of man and woman are 'Given'; because, they are elements of familiarity in these two ads. The 'New', on the other hand, are represented visually: pictures of two watches. It is only when the viewer reads the body copy or sees the emblem in these two ads that the watch is named. Once named and described verbally, the two watches become 'Given'.

\subsubsection{Visual Modality, Ideal and Real}

In terms of modality, the photographed image looks 'realistic'- the way he would look if we saw him in the real life. Based on what was stated by Simpson and Mayr (2010: 89) photographs that appear to be realistic, that represent the world as it is had we been there, are of high modality. This realizes the subject of the photograph. The advertisement displays an 'Ideal-Real' composition. The top part of these two ads, the 'Ideal part', consists of the picture of a famous driver and well known supermodel, two persons to be ideal for people and they like to be in their places and the bottom part provides the factual detail and a 'Real' picture of the product. In other words, the modality of the top and bottom part is different. The top picture shows what one would actually (high modality) like to be when they buy the product. It is placed in the Ideal.

\subsubsection{Framing}

From the point of view of framing, in the first ad, no significant 'disconnection' is observed between the photographed man and the watch image. In a sense that; there is no separation between these two images through frame lines or pictorial framing devices. According to Kress and van Leeuwen (2006: 203),"the absence of framing stresses group identity". No framing stresses the lack of separation between units of information. They state that,"the more the elements of the spatial composition are connected; the more they are presented as belonging together as a single unit of information"(ibid.). The same applies to the second ad (see appendix2) where no space between the photographed female and watch and the color harmony create a strong relation between the 'Ideal' and 'Real'.

The first ad is surrounded by much empty white space. Machin (2004) has suggested that this "use of space is more common in ads for men, connoting perhaps a minimalist form of interior design, in contrast with a more homely and 'feminine' physical design and layout" (cited in Simpson and Mayr 2010: 90).

\subsubsection{Size of Frame and Social Distance}

Kress and Leeuwen (2006: 124) point out that, "the choice of distance can suggest different relations between represented participants and viewers". 'Close personal distance' is the distance at which 'one can hold or grasp the other person' and therefore also the distance between people who have an intimate relation with each other (ibid: 124). In the case of ad1, the advertiser used the very close shot (or 'extreme close- up') which shows anything less than 
head and shoulders of the subject. Hence, it may make an intimate relation between the image and the viewer. The visual system of size of frame derives from the 'proximics', as Hall (1964) calls it, "of everyday face-to-face interaction".

\subsubsection{Power and Angle}

In both ads, both human images as well as the product photographed from a low angle, having symbolic power over us. According to Martin (1968: 37-8) "low angles generally give an impression of superiority, exaltation and triumph [...] high angles tend to diminish the individual, to flatten him morally by reducing him to ground level, to render him as caught in an isurmountable determinism" (cited in Kress and van Leeuwen 2006: 140). As a result, if the picture is at eye level, then the point of view is one of equality and there is no power difference involved. But, as mentioned by Kress and van Leeuwen, this is a matter of degree. In the first ad, the photographed man does not look straight on us. Here, the man is depicted as exercising symbolic power on us. In the second ad, the female model photographed in this ad looks down on us. It makes a kind of face to face communication. Hence, it could make an intimate relation between this represented sign and the viewers.

\subsubsection{Color}

A further point can be made about these ads and that is the way in which color has been used. In the first ad, it is obviously no accident that the product and the photographic image appear to have red color. According to Kress and Leeuwen (2006: 229), "color is primarily related to affect", and Halliday and others (e.g. Poynton, 1985; Martin, 1992) see affect as an aspect of the interpersonal metafunction. They believe that color is used metafunctionally, and it is therefore a mode in its own right. Color may play a key role in the success of one ad and seems to be the first thing the receivers notice. Advertisers use color to reflect a specific brand and, attempt to communicate a certain mood dictated by the product itself. From ideational perspective, "color clearly can be used to denote people, places and things as well as classes of people, places and things, and more general ideas"(Kress \& Leeuwen 2006: 229). "Again color is also used to convey' interpersonal' meaning [...]. It can be and is used to do things to or for each other" (ibid.). It shows the 'personality' of a product which is often a lot harder to come up with. Colors and their underlying sociological and historical connotation certainly do produce specific reactions in particular contexts - emotions, associations and even physical effects that can help advertisers in their quest for ever more accurate targeting. Using proper color seems to be the quickest way to create mood without saying a word.

According to Kress (2010: 88) "most of us [...] have quite a strong sense of the meanings of color; which is to say that we could easily articulate what such meanings are". Red and black are the predominant colors in the first ad which is somewhat ironic given that the ad stress that the watch contains these colors. The watch behind the photographic picture may serve to reinforce this claim. In result, there exists color coherence in the first advertisement. Repetition of one color, black, is used to promote textual cohesion. Using the red color in this ad could also represent ideational function; because, it is used to denote the 'OMEGA' company as its emblem has the same color and will signal its identity. Simpson and Mayr (2010: 89) believe that, "looking at what is hidden or made less important or what is 
enhanced (e.g. colors) can tell us about the world that is created for us".

Walters et al. (1982) found a link between red and felt excitement. This is consistent with the generally accepted view that red is an exciting color (e.g., Guilford and Smith 1959; Tom et al. 1987). This feeling of excitement is pleasant and likely to lead to favorable attitudes. Then, it represent interpersonal function in a sense that it is used to act on others. The background is simple, neutral color. Again a connection is being made between the image in the ad and the commodity, watch.

The golden color is the dominant color of the ad2, which in turn implies the ironic given that the absolute color of the product has golden result. One image of the product may enhance this claim. The advertiser has used plain, 'unmodulated' or 'decontextualized' color for the background. The background is less articulated than the foreground. According to Kress and van Leeuwen (2006: 161), "when the background is sharper [...], a somewhat artificial, more than real impression results. Hence, the modality of background is lower than the modality of foreground". The portrait of the woman in this ad is a close shot. She is depicted in a personal way. If this was all we could see of her in reality, we would be close enough to touch her. As for the case of ad1, it will make an intimate distance with the viewers.

\section{Conclusion}

The signs in these two ads are too ambiguous, too 'polysemic' (multiple in their meanings) to decide on one 'true' meaning of the ads. These factors, which have to do with the social context of ads and of their readers, "make any reading of an ad as a self-contained system of signs with a determinable ideological effect very difficult to justify as 'true'" (Bignell, 2002: 5). Beasley and Danesi (2002: 31) points out that, "semiotics ultimately allows us to filter the implicit meanings ad images that swarm and flow through us every day, immunizing us against becoming passive victims of a situation. By understanding the images, the situation is changed, and we become active interpreters of signs."

The result of such a study reveals that signs in an advertisement can form message- entities which are internally coherent and which cohere with their environment, the textual function. They can also represent meaning about the social relations of those engaged in communication, the interpersonal function. For pursuing ideational function, they can represent meanings about the world of states, actions and events. The major conclusion to be drawn from this study is that, by using signs and colors, advertisers could better communicate with consumers and make the product more popular among them in order to achieve the goal of ever-lasting purchase and popularity. There is regularity to be found in advertising phenomena, sets of signs organizing, constraining choice, and these choices are part of social meaning. These sets of signs do not make up a single, comprehensive and coherent meaning, and the meaning of particular signs is always relative to specific kinds of reader and; on specific occasions. In terms of this scheme, semiotic analysis occupies an important place within a common framework of critical discourse analysis of advertising. Here, the attention is on signs as a carrier of ideological meanings. Ideologies are systems of claims. Claims are manipulated images. Images are forms of action. What is required is a form of close semiotic description that is at the same time a precise account of the transactions that constitute social 
meanings. This research is only a step along the way. There is one further, last point. Semiotic works have social affect and in order to reach this end, they serve different kinds of modes as semiotic resources. The image, word and color, seen in this way as the product of social practices, are just three of the many semiotic modes through which social meanings of ads are coded. Semiotic reference occupies a pivotal point in the relationship between advertising discourse and ideology. Semiotic analyses like those examined in this paper are perhaps basic building block in constructing ideologies.

\section{Acknowledgements}

The authors are deeply grateful to anonymous reviewers for their invaluable critical comments on earlier drafts of this article.

\section{References}

Bell, A. \& Garret, P. (1997). Approaches to Media Discourse. In G. Kress \& T. Van Leeuwen (Eds.), Chapter 7 Front Pages: The (critical) analysis of newspaper layout. Oxford: Blackwell Publishers

Beasley, R. \& Danesi, M. (2002). Persuasive Signs: the Semiotic of Advertising. Berlin: Moutor de Gruyter. Retrieved from http:// www. books. google.com/ books? id= as1r7kC.

Bernestein, D. (1974). Creative Advertising. London: Longman.

Bignell, J. (2002). Media Semiotics: an Introduction. Manchester: Manchester University Press. pp. 31-78. Retrieved from http:// www. books. google.com/ books? id= MGom6ENJRLkI.

Bloor, T. \& Bloor, M. (2007). The Practice of Critical Discourse Analysis: An Introduction. London: Hodder education.

Cook, G. (1992). The Discourse of Advertising. London: Routledge.

Delin, A. (2000). The Language of Everyday Life. London: Sage.

Durant, A. \& Lambrou, M. (2009). Language and Media. London: Routledge.

Dyer, G. (1986). Advertising as Communication. London: Routledge.

Eaglton, T. (1991). Ideology: an Introduction.p.195. Retrieved from http:// www. books.google.com/books?id= JK2L8zoHFeIL.

Fairclough, N. (2003) Analysing Discourse: Textual Analysis for Social Research. London: Routledge.

Fairclough, N. \& Wodak, R. (1997). Critical Discourse Analysis. In P. Simpson \& A. Mayr (Eds.), Language and Power. London: Routledge.

Fiske, J. (1990). Introduction to Communication Studies (2nd ed.). London: Routledge.

Fowler, R. (1985). Power. In: Van Dijk, T. A. (Ed.) Handbook of Discourse Analysis. 
Academic Press, London, pp. 61-83.

Goatly, A. (2000). An Introduction Coursebook: Critical Reading and Writing. London: Routledge.

Goldman, R. (1992). Reading Ads Socially. London: Routledge.

Guilford, J. P. \& Smith, P. C. (1959). A system of color preferences. American Journal of Psychology, 72(4), pp. 487-502.

Halliday, M. (1994). An introduction to functional grammer (2 nd edition). London: Edward Arnold. p.36.

Harris, A. C. (1981). From Linguistic Theory to Meaning in Educational Practice. Unpublished dissertation. (Los Angeles: University of California at Los Angeles). Retrived from http:// www.csun.edu/ vcspc005/advertise.html

Hodge, R. \& Kress, G. (1988). Social Semiotics. New York: Cornel University Press.

Hodge, R. \& Kress, G. (1993). Language as Ideology. London: Routledge.

Jefkins, F. (1994). Advertising. London: Pitman.

Kress, G. (2010). Multimodality: A Social Semiotic Approach to Contemporary

Communication. London: Routlege.

Kress \& van Leeuwen, T. (2001). Multimodal Discourse: the Modes and Media of contemporary Communication. London: Hodder Arnold.

Kress, G \& van Leeuwen, T. (2006). Reading Images, the Grammar of Visual Design (2 nd ed.). London: Routledge.

Machin, D. \& van Leeuwen, T. (2004). Global Media: generic homogeneity and discursive diversity. Continuum Journal of Media and Cultural Studies, 18(1), pp. 99-120.

Martin, J.R (1985). Factual writing. Geelong: Deakin University Press.

Martin, M. (1968). Le Language cinematographique. Paris: Editions du Cerf.

Morris, J., \& Hirst, G. (1991). Lexical cohesion computed by the aural relations as an indicator of the structure of text. Computational Linguistics, 17, pp. 21-48.

Poynton, C. (1985). Language and Gender: Making the Difference,. Geelong: Deakin University Press.

Saren, M., Maclaran, P., Goulding, C., Elliott, R., Shankar, A. \& Catterall, M. (eds) (2007). Critical Marketing. Defining the Field. Oxford: Elsevier.

Simpson, P. \& Mayr, A. (2010). Language and Power. London: Routledge.

Tom, G., T. Barnett, W. Lew, \& Selmants, J. (1987). Cueing the Consumer: The Role of Salient Cues in Consumer Perception, J. Consumer Marketing, 4(2), pp.23-27. 


\section{Macrothink}

International Journal of Industrial Marketing

ISSN 2162-3066 2011, Vol. 1, No. 1

Van Dijk, T.A. (1991). Racism and the Press. London: Routledge.

Van Leeuwen, T. (2005). Introducing Social Semiotics. London: Routledge.

Walters, J., Apter, M. J. \& Svebak, S. (1982). Color Preference Arousal, and the Theory of Psychological Reversals. Motivation and Emotion, 6(3), pp. 193-215.

Williamson, J. (1978). Decoding Advertisements; Ideology and Meaning in Advertising. London: Marion Boyars.

Time magazine, October 15, 2002 www.timeeurope.com 


\section{Macrothink Institute $^{T M}$}

Appendix1. Advertisement of 'OMEGA' watch extracted from 'Time' magazine (2002)

\section{Michael Schumacher's Choice}

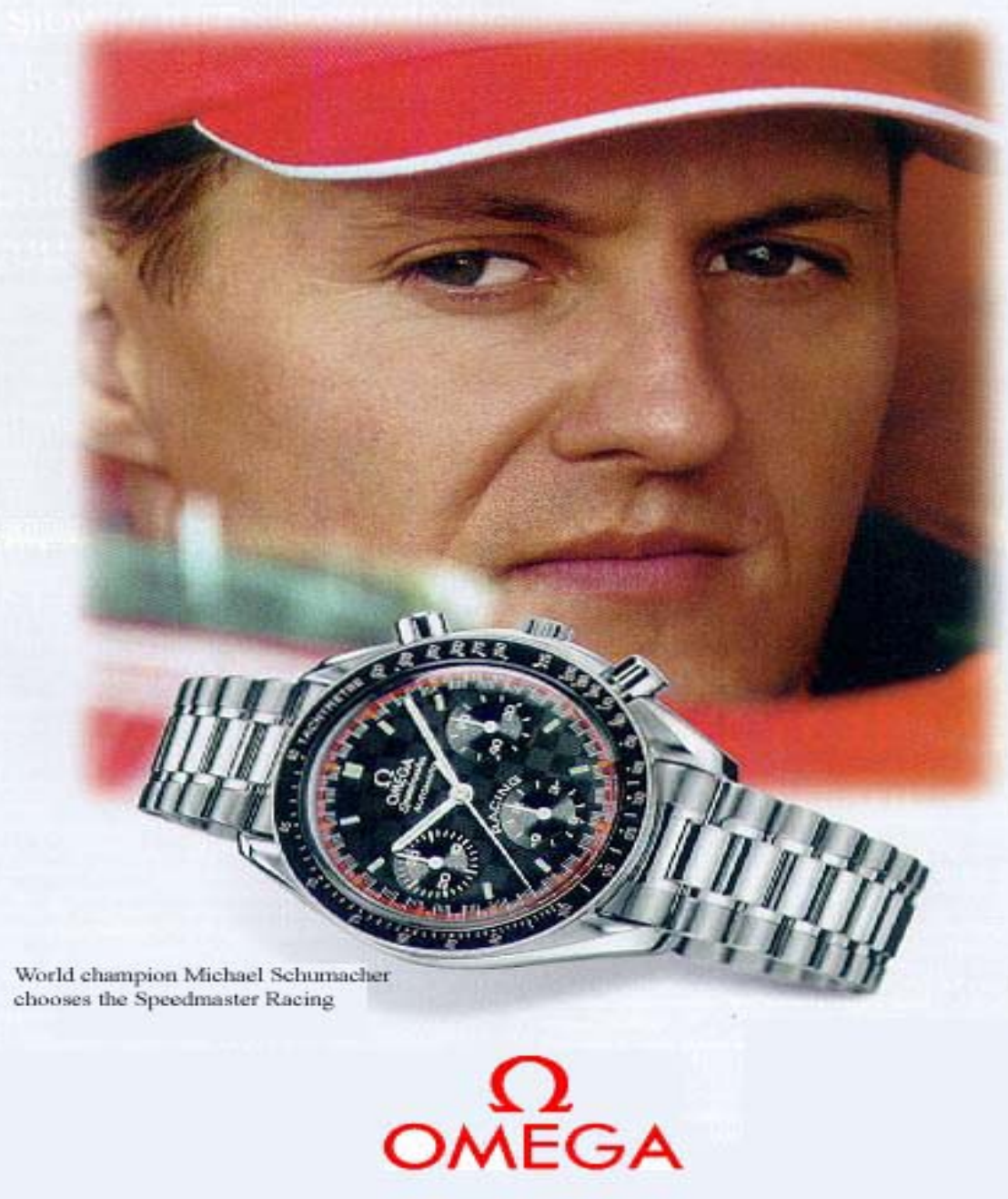




\section{Macrothink}

Appendix2. Advertisement of 'OMEGA' watch extracted from 'Time' magazine (2002)

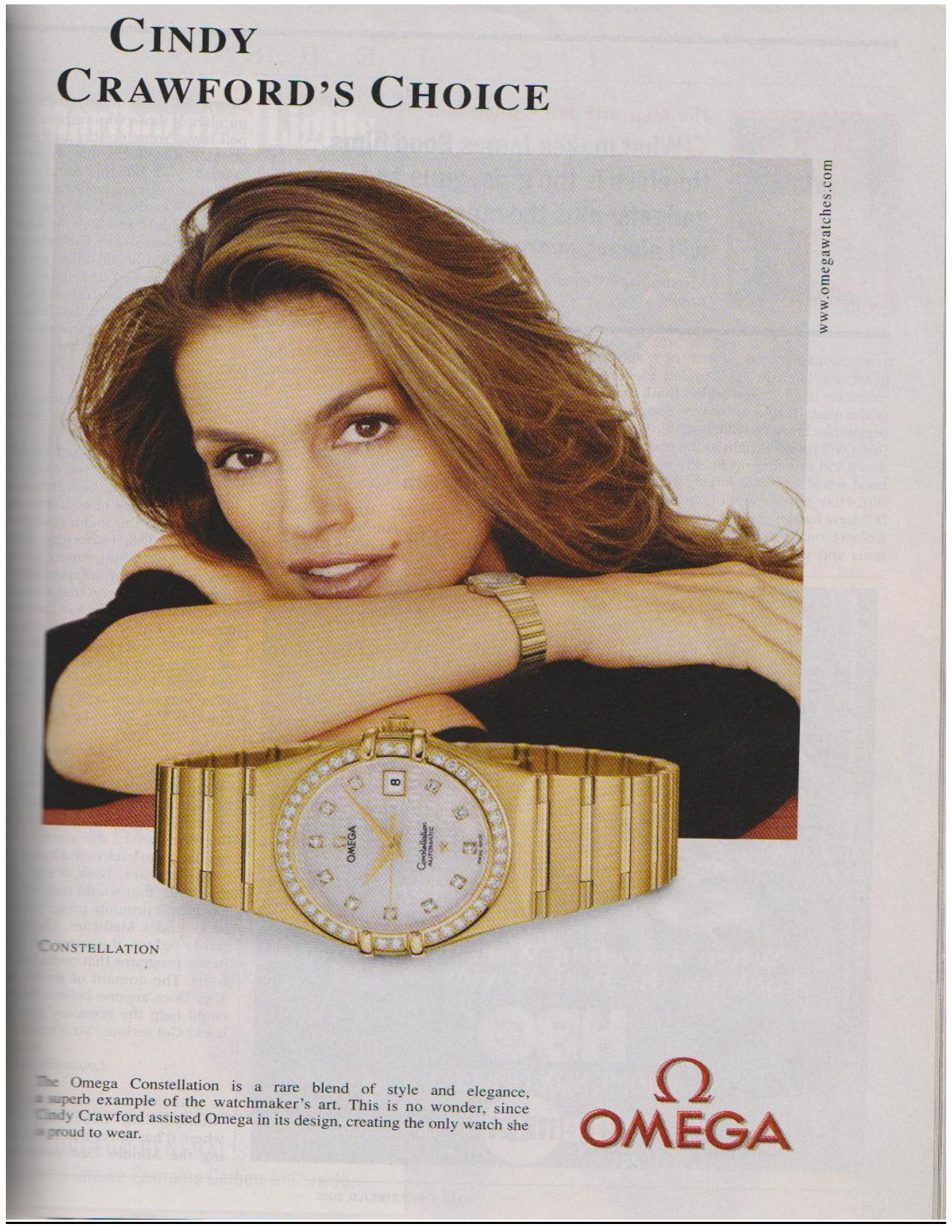

\section{Copyright Disclaimer}

Copyright reserved by the author(s).

This article is an open-access article distributed under the terms and conditions of the Creative Commons Attribution license (http://creativecommons.org/licenses/by/3.0/). 